\title{
Pengaruh Perbedaan Bentuk Scrotal Bipartition terhadap Kualitas Semen pada Kambing Kejobong
}

\author{
R. H. Sulaksono ${ }^{1 \mathrm{a}}$, E. T. Setiatin ${ }^{1}$ dan E. Kurnianto ${ }^{1}$ \\ ${ }^{I}$ Laboratorium Genetika, Pemuliaan dan Reproduksi, Fakultas Peternakan dan Pertanian UNDIP \\ a email: kurniantoedy17@gmail.com
}

\begin{abstract}
Abstrak
Penelitian bertujuan untuk menganalisis kualitas semen dari bentuk skrotum yang berbeda (bipartisi) pada kambing Kejobong. Tiga puluh ekor kambing Kejobong jantan digunakan sebagai materi penelitian. Populasi sasaran yang dituju adalah kambing Kejobong yang berada di Kecamatan Kejobong, Kabupaten Purbalingga, Jawa Tengah. Sampel ditentukan berdasarkan purposive sampling. Pengamatan pertama dengan melihat perbedaan bentuk skrotum yaitu no bipartition (NB) dan bipartition up to $50 \%(\mathrm{~B}<50 \%)$. Pengukuran skrotum meliputi panjang, lebar, dan lingkar. Pengamatan lain dilakukan terhadap kualitas semen yang meliputi uji makrospis dan uji mikroskopis. Data yang diperoleh dianalisis dengan independent t-test. Hasil penelitian menunjukkan bahwa ukuran skrotum pada kedua bentuk bipartisi menunjukkan perbedaan nyata $(\mathrm{P}<0,05)$ pada kualitas makroskopis semen. Sementara itu, pada uji mikrokopis semen parameter abnormalitas, gerak individu, dan konsentrasi tidak berbeda nyata, tetapi $\mathrm{pH}$, sperma hidup dan mati berbeda nyata $(\mathrm{P}<0,05)$. Disimpulkan bahwa bentuk bipartisi skrotum yang berbeda mempengaruhi ukuran skrotum dan kualitas makroskopis, dan sebagian kualitas mikroskopis semen kambing Kejobong.
\end{abstract}

Kata Kunci : bipartition, uji kualitas semen, kambing Kejobong

\section{Efffect Differences of Scrotal Bipartition Shape on Semen Quality in Kejobong Goat}

\begin{abstract}
Abstrack
This aim of research was to analysis the semen quality of different Kejobong goat scrotum form. Thirty buck of Kejobong goat were used as the materials. Those materials were originated from Kejobong District, Purbalingga Regency, Central Jawa. The samples were taken on the basis of different form of scrotum, that was no bipartition (NB) and bipartition up to $50 \%(B<50 \%)$. The scrotum measurements consisted of lenght, widht, and circumference. Semen quality were observed by macrocopic and microscopic examination. The results showed that scrotum size for both of bipartition form was significantly different $(P<0.05)$ in macroscopic semen quality. The microscopis test of semen quality in the abnormality, individual movements and concentration was not significantly different, however volume, $p H$ live and dead sperm were significantly different $(P<0.05)$ In conclusion, the different of bipartition form affected the scrotum size and macroscopic semen quality, few of microscopic parameter in Kejobong goat.
\end{abstract}

Key word : bipartition, test the quality of semen, Kejobong goat

\section{Pendahuluan}

Kambing Kejobong merupakan kambing asli lokal Indonesia yang berasal dari Pubalingga, Jawa Tengah (Setiaji dkk., 2013). Kambing yang merupakan hasil persilangan antara kambing PE (Peranakan Ettawa) dengan kambing Kacang ini mempunyai bentuk tubuh yang bulat disertai tingkat pertumbuhan relatif lebih cepat. Kambing kejobong mempunyai karakteristik, yaitu ukuran tubuh lebih besar dibandingakan dengan kambing Kacang, diharapakan dapat informasi tentang kualitas kemudian warna hitam polos, dan kepala kambing Kejobong seperti kambing PE (Sodiq, 2009).

Indikator yang mencerminkan adanya potensi reproduksi pada ternak ruminansia adalah dengan mengetahui lingkar skrotum (LgS). Lingkar skrotum (LgS) berhubungan dengan potensi produksi spermatozoa dan testosteron (Syamyono dkk., 2014). Dengan mengetahui ukuran skrotum dan kuantitas semen yang baik. Lingkar 
skrotum ( $\mathrm{LgS}$ ) memiliki hubungan erat dengan potensi produksi semen pejantan.

Semen merupakan cairan yang mengandung spermatozoa dan plasma semen yang disekresikan oleh kelenjar kelamin didalam testes. Semen kambing hanya bertahan sekitar 1-2 jam setelah koleksi (Husin dkk., 2007). Salah satu seleksi pejantan yang baik dengan cara uji kualitas semen.

Untuk pengamatan uji kualitas semen dilakukan setelah pengambilan semen dari kambing. Ada dua cara uji kualiatas semen, dengan pemeriksaan secara makroskopis dan mikroskopis. Pemeriksaan makroskopis meliputi pemeriksaan warna, konsistensi, $\mathrm{pH}$, bau, dan volume, pemeriksaan secara mikroskopis mencangkup pemeriksaan gerak massa, gerak individu, hidup - mati, konsentrasi, dan abnormalitas (Susilawati, 2011). Kualitas semen yang baik sangat berpengaruh dalam hal keberhasilan perkawinan seekor pejantan (Tambing dkk., 2003). Tujuan penelitian untuk menganalisis kualitas semen berdasarkan bentuk skrotum yang berbeda pada kambing Kejobong.

\section{Materi dan Metode}

Materi penelitian yang digunakan yaitu 30 ekor kambing Kejobong. Penelitian dilakukan dengan metode observasional dimana pengamatan dan pengumpulan data dilakukan secara langsung terhadap objek penelitian. Populasi sasaran yang dituju yaitu ternak kambing Kejobong yang berada di Kabupaten Purbalingga. Sampel ditentukan menggunakan purposive sampling yang diambil berdasarkan kriteria tertentu yaitu: lokasi penelitian dipilih berdasarkan wilayah dengan populasi kambing Kejobong terbanyak dan merupakan wilayah pengembangan ternak

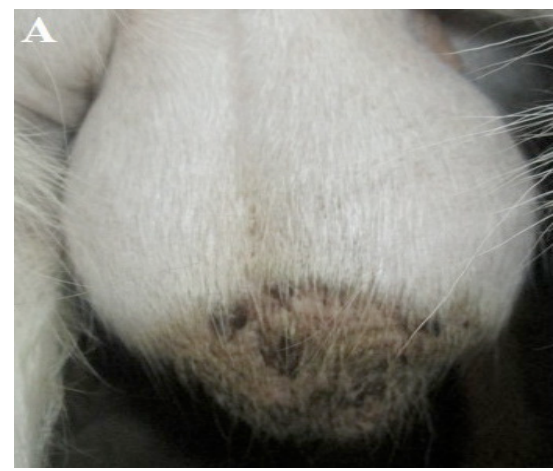

kambing Kejobong. Menurut Jansen and Van der Burg (2004), kambing dengan poel 1- 4 antara umur 1,8>36 bulan, syarat kambing yang dijadikan sampel adalah kambing kambing yang mempunyai bentuk skrotum berbeda.

Pengamatan skrotum dilihat berdasarkan bentuknya, yang dibedakan menjadi dua, yaitu no bipartition (NB) dan yang bipartition up to $50 \%(\mathrm{~B}<50 \%)(\mathrm{Gambar}$ 1). Cara pengukuran skrotum menggunakan pita ukur yaitu dengan menempelkan pita ukur ke kulit skrotum lalu mulai pengamatan panjang, lebar, dan lingkar. Pengukuran panjang skrotum $(\mathrm{PgS})$ berawal dari pangkal skrotum sampai ke ujung bagian bawah skrotum dengan mengikuti bagian tekstur kulit skrotum. Pengukuran lebar skrotum (LbS) mencakup kanan dan kiri. Pengukuran lebar skrotum (LbS) dimulai bagian belahahan skrotum sampai meliputi bagian samping skrotum. Pengukuran lingkar skrotum ( $\mathrm{LgS}$ ) dilakukan dengan cara mengukur skrotum secara melingkar dari bagian tengah, depan, belakang sampai dengan bagian tengah lagi. Pengukuran Pgs, LbS, dan LgS dilakukan tiga kali.

Penampungan semen segar dilakukan dengan menggunakan vagina buatan. Pengamatan uji kualitas semen dilakukan dua tahap yaitu uji makrokopis dan mikrokopis. Uji makrokopis meliputi warna, konsistensi, $\mathrm{pH}$, bau, dan volume, sedangkan uji mikrokopis meliputi uji gerak massa, gerak individu, hidup - mati, konsentrasi, dan abnormalitas. Data yang didapat dianalisis dengan menggunakan t-test independen (Sudjana, 2002) untuk membedakan ukuran ukuran kedua bentuk skrotum.

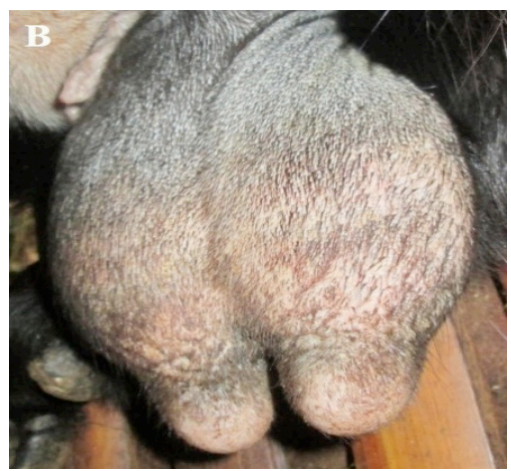

Gambar 1. Bentuk skrotum. A: no bipartition (NB); B: bipartition up to $50 \%(\mathrm{~B}<50 \%)$. (Diadopsisi dari Jùnior dkk. (2009). 


\section{Hasil dan Pembahasan \\ Ukuran Skrotum}

Data ukuran - ukuran skrotum disajikan pada Tabel 1. menunjukkan bahwa ukuran skrotum bagian kanan dan kiri yang meliputi lingkar skrotum (LgS), lebar skrotum (LbS), panjang skrotum (PgS) NB dan $\mathrm{B}<50 \%$ memiliki perbedaan yang nyata $(\mathrm{P}<0,05)$. Menurut Kostaman dkk. (2004) menyatakan lingkar skrotum (Lgs) memiliki hubungan yang sangat erat dengan potensi produksi semen pejantan. Syamsono dkk. (2014) menyatakan bahwa lingkar skrotum (Lgs) digunakan sebagai salah satu parameter seleksi pejantan. Dengan hal ini pengukuran skrotum kambing bisa mendapatkan informasi yang berkaitan dengan potensi produksi seekor pejantan kambing. Pejantan yang memiliki ukuran skrotum yang besar akan menghasilkan volume yang banyak dibandingkan ukuran skrotum yang kecil. Penelitian yang dilakukan oleh Latif (2009) pada sapi potong memperlihatakan lingkar skrotum (LgS) berkorelasi kuat dengan volume semen yaitu sebesar 0,72 , yang artinya makin besar ukuran skrotum, makin tinggi volume semen. Hasil pengukuran skrotum kambing Kejobong NB $(\mathrm{n}=14)$ dan $\mathrm{B}<50 \%(\mathrm{n}=16)$ disajikan pada Tabel 1.

\section{Uji Kualitas Semen}

Hasil pengamatan uji kualitas semen secara makroskopis dan mikroskopis pada kambing Kejobong NB $(\mathrm{n}=14)$ dan $\mathrm{B}<50 \%$ $(\mathrm{n}=16)$ disajikan pada Tabel 2.

\section{Uji Makroskopis}

Hasil pengamatan warna, uji makroskopis pada kambing Kejobong menunjukkan bahwa kedua bentuk bipartisi memiliki hasil yang berbeda pada kedua bentuk skrotum. Pada NB warna krem 50\%, putih susu $42,85 \%$, putih bening $7,14 \%$, sementara pada $\mathrm{B}<50 \%$ warna krem $56,25 \%$, putih susu $43,75 \%$ dan putih bening $0 \%$. warna, konsistensi, $\mathrm{pH}$, bau, dan volume. Hal ini menunjukkan bahwa semen pada kedua bentuk bipartisi masih dalam keadaan normal. Syamsono dkk. (2014) menyatakan bahwa warna semen kambing Kejobong secara umum memiliki warna krem dan memiliki kosistensi yang kental. Warna semen yang keruh menunjukkan bahwa jumlah spermatozoa yang semakin tinggi. Dethan dkk. (2010) menyatakan bahwa warna pada semen berhubungan dengan tingkat konsentrasi dan konsistensi pada spermatozoa.

Tingkat konsistensi semen kedua bentuk bipartisi memiliki hasil yang berbeda. Hasil pengamatan tingkat konsistensi bentuk NB yang kental $57,14 \%$ dan encer $48,25 \%$, sedangkan bentuk $\mathrm{B}<50 \%$ kental $31,25 \%$ dan encer $68,75 \%$. Tingkat konsistensi dengan kekentalan yang lebih tinggi menunjukkan jumlah spermatozoa yang lebih banyak. Purwasih dkk. (2013) menyatakan bahwa kekentalan atau konsistensi beserta sifat-sifat semen berbanding sama dengan konsentrasi spermatozoa. Suyadi dkk. (2012) menyatakan bahwa semen dengan kadar konsistensi kental akan mempunyai tingkat konsentrasi spermatozoa yang tinggi dibandingkan dengan konsistensi yang encer.

Tingkat keasaman $(\mathrm{pH})$ semen kambing Kejobong hasil penelitian ini masih termasuk dalam kondisi normal, walaupun pada kedua bentuk skrotum menunjukkan berbeda nyata $(\mathrm{P}<0.05)$ pada bentuk NB dan $\mathrm{B}<50 \%$. Menurut Syamyono dkk. (2014), tingkat keasaman semen kambing Kejobong dewasa yaitu $6,8 \pm 0,17$.

Tabel 1. Ukuran skrotum

\begin{tabular}{cccc}
\hline Variabel & NB $(\mathrm{n}=14)$ & $\mathrm{B}<50 \%(\mathrm{n}=16)$ & Uji-t \\
\hline Skrotum Kanan & & & \\
Panjang $(\mathrm{cm})$ & $12,60 \pm 1,76$ & $13,65 \pm 1,63$ & $27,35^{*}$ \\
Lebar $(\mathrm{cm})$ & $4,89 \pm 1,05$ & $5,08 \pm 0,71$ & $83,68^{*}$ \\
Lingkar $(\mathrm{cm})$ & $13,11 \pm 1,57$ & $14,25 \pm 1,72$ & $32,48^{*}$ \\
Skrotum Kiri & & & \\
Panjang (cm) & $12,81 \pm 1,92$ & $13,55 \pm 1,39$ & $19,63^{*}$ \\
Lebar $(\mathrm{cm})$ & $5,13 \pm 1,10$ & $5,74 \pm 0,74$ & $52,23^{*}$ \\
Lingkar $(\mathrm{cm})$ & $13,28 \pm 1,61$ & $14,46 \pm 1,63$ & $34,26^{*}$ \\
\hline
\end{tabular}

$*=$ Berbeda nyata; $\mathrm{NS}=$ tidak beda nyata;

NB: No bipartition; $\mathrm{B}<50$ : Bipartition up to $50 \%$ 
Tabel 2. Rata-rata Hasil Evaluasi Semen Kambing Kejobong dengan Bentuk Skrotum yang Berbeda

\begin{tabular}{lccc}
\hline \multirow{2}{*}{ Variabel Pengamatan } & \multicolumn{2}{c}{ Nilai Rata-rata Uji Kualitas Semen } & \multirow{2}{*}{ Uji-t } \\
\cline { 2 - 3 } Makroskopis: & $\mathrm{NB}(\mathrm{n}=14)$ & $\mathrm{B}<50 \%(\mathrm{n}=16)$ & \\
Warna (\%) & & & \\
$\quad$ Krem & 50 & 56,25 & \\
Putih Susu & 42,85 & 43,75 & \\
$\quad$ Putih Bening & 7,14 & 0 & \multirow{2}{*}{$29,99^{*}$} \\
Konsistensi (\%) & 57,14 & 31,25 & \\
$\quad$ Kental & 48,25 & 68,75 & \\
Encer & $6,42 \pm 0,75$ & $6,68 \pm 0,87$ & \\
pH & & & \\
Bau (\%) & 85,71 & $93,77^{*}$ \\
Spermin & 14,28 & 6,25 & \\
Amis & $0,68 \pm 0,35$ & $0,68 \pm 0,23$ & \\
Volume (mL) & & & \\
& & & \\
Mikroskopis: & & & \\
Gerak Massa (\%) & 28,57 & 12,5 & \\
$\quad+$ & 35,71 & 50 & \\
$\quad++$ & 35,71 & 37,5 & \\
$\quad+++$ & $60,07 \pm 3,38$ & $60,41 \pm 1,68$ & \\
Gerak Individu (\%) & $54,92 \pm 5,46$ & $52,11 \pm 7,51$ & $5,09^{*}$ \\
Hidup (\%) & $35,06 \pm 5,46$ & $37,14 \pm 6,02$ & $4,84^{*}$ \\
Mati (\%) & $1429,92 \pm 601,00$ & $1431,62 \pm 520,41$ & $0,00^{\mathrm{NS}}$ \\
Konsentrasi (juta/mL) & $14,26 \pm 4,24$ & $14,50 \pm 6,12$ & $0,66^{\mathrm{NS}}$ \\
Abnormalitas (\%) & & & \\
\hline
\end{tabular}

* Berbeda nyata dan NS tidak nyata.

NB: No bipartition; $\mathrm{B}<50 \%$ : Bipartition up to $50 \%$

Dethan dkk. (2010) menyatakan bahwa tingkat keasaman $(\mathrm{pH})$ sangat bervariasi tergantung spesies ternak. Menurut hasil pengamatan bau semen kambing Kejobong bentuk NB memiliki kadar bau spermin $85,71 \%$ dan bau amis $14,28 \%$, sedangkan $\mathrm{B}<50 \%$ memiliki kadar bau spermin $93,75 \%$ dan bau amis $6,25 \%$. Rahayu dkk. (2014) menyatakan bahwa umumnya bau semen dinyatakan dengan bau khas, semen yang bagus kualitasnya tentu akan memiliki bau yang khas. Hal ini menunjukkan kualitas semen bentuk $\mathrm{B}<50 \%$ lebih baik dari pada bentuk NB.

Volume semen kambing Kejobong memiliki hasil yang berbeda nyata $(\mathrm{P}<0.05)$ pada kedua bentuk NB dan $\mathrm{B}<50 \%$. Volume semen hasil penelitian ini lebih banyak dari pada yang dinyatakan oleh Husin (2007), bahwa volume semen kambing berkisar antara $0,3-0,5 \mathrm{~mL}$. Menurut pendapat Prayogo dkk. (2013), testis merupakan organ reproduksi primer yang memproduksi spermatozoa menjadi lebih penting. Heriyanta dkk. (2013) menambahkan bahwa aktivitas spermatogenesis yang semakin tua akan semakin menurun sehingga volume semen rendah.

\section{Uji Mikrokopis}

Hasil pengamatan gerak massa semen kambing Kejobong pada kedua bentuk bipartisi memiliki hasil yang berbeda. Pada bentuk NB diperoleh gerak massa $+28,57 \%$, $++35,71 \%$, dan $+++35,71 \%$. Sedangkan pada $\mathrm{B}<50 \%$ diperoleh gerak massa $+12,5 \%$, ++ $50 \%$, dan $+++37,5 \%$. Hal ini menunjukkan setiap bentuk bipartisi memiliki perbedaan dan bervariasi setiap ekornya. Menurut Dethan dkk. (2010) gerak massa + jika tidak terlihat gelombang melainkan hanya gerak individual. Gerak massa ++ menunjukkan gelombang tipis, jarang, kurang jelas, dan bergerak lamban, +++ gelombang besar, banyak, gelap, tebal, dan aktif. Secara keseluruhan gerak massa pada kambing Kejobong sangat baik untuk kedua bentuk bipartisi, karena skor ++ dan +++ paling besar terdapat pada kambing Kejobong. Hal ini sesuai pendapat Tambing dkk. (2003) bahwa semakin tebal dan besar 
gelombang spermatozoa maka semakin aktif dan banyak spermatozoa yang bergerak ke depan (motil progresif).

Gerak individu semen kambing Kejobong memiliki hasil yang tidak berbeda nyata untuk kedua bentuk bipartisi. Pada NB $60,07 \pm 3,38$ dan $\mathrm{B}<50 \% 60,41 \pm 1,68$. Pengaruh gerak individu sperma dapat disebabkan oleh suplai energi dalam sperma. Hal ini sesuai pendapat Purwasih dkk. (2013) gerak individu sperma sangat dipengaruhi oleh ketersediaan suplai energi sperma yang dihasilkan dalam metabolisme berupa ATP.

Persentase hidup mati semen kambing Kejobong memiliki hasil yang berbeda nyata $(\mathrm{P}<0.05)$ dari kedua bentuk skrotum NB dan $\mathrm{B}<50 \%$. Untuk mengetahui persentase hidup mati semen kambing menggunakan cairan eosin. Menurut Mulyono (1998) bahwa semen yang mati akan menyerap cairan eosin, sedangkan pada semen yang hidup tidak menyerap cairan eosin. Aminah dan Layla (2000) menyatakan bahwa penyebab persentase hidup semen yang rendah adalah suhu, cahaya, dan kecepatan waktu dalam proses perwarnaan.

Konsentrasi semen kambing Kejobong pada kedua bentuk tidak berbeda nyata dari hasil pengamtan di dapatkan untuk bentuk NB dan pada bentuk $\mathrm{B}<50 \%$. Penilaian kosentrasi semen sangat penting, karena sebagai kriteria penentu kualitas semen. Menurut pendapat Wildeus (1995) konsentrasi sperma setiap ejakulasi berkisar 1,5-5,0 x 109 spermatozoa / mL. Tingkat kosentrasi semen kambing yang tinggi dapat diketahui melalui kadar konsistensi atau kadar kekentalan. Hal ini sesuai pendapat Partodiharjo (1992) bahwa tingkat kekeruhan pada semen kambing tergantung pada kosentrasi spermatozoa semakin keruh maka jumlah semen semakin banyak.

Berdasarkan hasil yang diperoleh, tingkat abnormalitas pada kambing Kejobong tidak berbeda nyata pada kedua bentuk bipartisi. Hasil analisis uji abnormalitas menunjukkan kuliatas semen kambing Kejobong termasuk kategori baik. Syamsono dkk. (2014) menyatakan bahwa kadar abnomalitas spermatozoa yang dalam keadaan normal yaitu 8-10\%. Dethan dkk. (2010) menyatakan bahwa abnormalitas spermatozoa merupakan kelainan fisik spermatozoa yang disebabkan oleh pembentukan spermatozoa didalam tubuli seminiferi ataupun karena proses perjalanan spermatozoa melalui saluran organ kelamin jantan. Menurut Tambing dkk. (2000) bahwa abnormalitas spermatozoa ditandai dengan adanya kelainan pada kepala dan ekor.

\section{Kesimpulan}

Bentuk bipartisi skrotum yang berbeda mempengaruhi ukuran skrotum, kualitas makroskopis, dan sebagian kualitas mikroskopis semen kambing Kejobong.

\section{Daftar Pustaka}

Aminah, S., dan Z. Layla. 2000. Teknik menghitung jumlah sel spermatozoa yang hidup dari semen kambing dengan perwarna eosin. Balai Peneliti Ternak. Bogor. Hal 136-139.

Dethan, A., A. Kustono dan H. Hartadi. 2010. Kualitas dan kuantitas sperma kambing Bligon jantan yang diberi pakan rumput gajah dengan suplementasi tepung darah. Buletin Peternakan 34(3):145153.

Heriyanta, E., M. Nur Ihsan, dan N. Isnaini. 2013. Pengaruh umur kambing Peranakan Etawa (PE) terhadap kualitas semen segar. J. Ternak Tropika. 14(2): $1-5$.

Husin, N., S. Tatik dan Kususiyah. 2007. Uji kualitas semen kambing nubian dan peranakannya (kambing Nubian x PE) serta kambing Boer berdasarkan lama penyimpanan. J. Sain Peternakan Indonesia. 2(2):57-21.

Jansen, C and K. Van der Burg. 2004. Goat Keeping in the Tropics. Agromisa Foundation, Wageningen.

Júnior. A. A. N. M., M. A. Miglino., D. J. A. Menezes., A. C. A. Neto., R. Leiser., R. A. B. Silva and M. A. M. Carvalho. 2009. Influence of the bipartite scrotum on the testicular and scrotal temperatures in goats. Pesquisa Veterinaria Brasileira. 29(10):797 802.

Kostaman. T., M. Martawidjaja., I. Herdiawan dan I. K. Sutama. 2004. Hubungan antara lingkar scrotum dengan bobot badan, volume semen, mortilitas progresif dan konsentrasi sprematozoa pada kambing jantan muda. Seminar Nasional Teknologi Peternakan dan Veteriner.

Latif, M.A., J.U. Ahmed., M.M.U. Bhuiyan 
and M. Shamsuddin. 2009. Relationship between scrotal circumference and semen parameters in crossbred bull. The Bangladesh Vet. 26(2):61-67.

Mulyono, S. 1998. Teknik Pembibitan Kambing dan Domba. Penebar Swadaya. Jakarta.

Ningrum., A. Praba, Kustono dan M. Hammam. 2008. Hubungan antara lingkar skrotum dengan produksi dan kualitas sperma pejanyan Simmental di Balai Inseminasi Buatan Ungaran, Jawa Tengah. Buletin Peternakan. 32(2):85-90.

Partodiharjo, S. 1992. Ilmu Produksi Hewan. Mutiara. Jakarta.

Prayogo, Ketu. U. E., T. R. Tagama dan Maidaswar. 2013. Hubungan ukuran lingkar skrotum dengan volume semen, konsentrasi dan motilitas sprematozoa pejantan sapi Limosin dan Simmental. J. Ilmiah Peternakan. 1(3):1050-1056.

Purwasih, R., Y. S. Ondho dan Sutopo. 2013. Efektivitas prefreezing semen sapi jawa sebagai parameter keberhasilan processing semen beku. J. Animal Agriculture. 2(1) : 44-50.

Rahayu, W., W. M. P. Agung dan G. Ciptadi. 2014. Kualitas semen segar kambing Boer pada temeperatur penyimpanan $4^{\circ} \mathrm{C}$ dengan menggunakan pengecer sitrat dan suplemen susu kedelai bubuk. Jurnal Biotropika. 2(1):55-60.

Setiaji. A, P. Suparman dan Hartoko. 2013. Produktivitas dan pola warna kambing kejobong yang dipelihara oleh peternak kelompok dan peternak individu. Jurnal Ilmiah Peternakan. 1(3): 89-795.

Sodiq. A. 2009. Karakterisasi sumberdaya kambing lokal khas Kejobong di Kabupaten Purbalingga propinsi JawaTengah. J. Agripet. 9(1):31-37.
Sudjana. 2002. Metode Statistika. Penerbit Tarsito, Bandung.

Susilawati, T. 2011. Spermatologi. UB Press, Malang.

Suyadi, A., Rachmawati., N. Iswanto. 2012. Pengaruh $\alpha$-TOCOPHEROL yang berbeda dalam pengenceran dasar TRISAMINOMETHANE - kuning telur terhadap kualitas semen kambing Boer yang disimpan pada suhu $5^{\circ} \mathrm{C}$. J. Ilmu Ilmu Peternakan. 22(3):1-8.

Suzanna, E. 2008. Kaji banding kualitas semen beku sapi potong yang telah didistribusikan ke lapangan. Fakultas Kedokteran Hewan, Institut Pertanian Bogor, Bogor. (Skripsi).

Syamyono, O., D. Samsudewa dan E. T. Setiatin. 2014. Korelasi lingkar skrotum dengan bobot badan, volume semen, kualitas semen, dan kadar testosteron pada kambing Kejobong muda dan dewasa. Buletin Peternakan. 38(3):132140.

Tambing, S. N., M. R. Toelihere., T. L. Yusuf dan I. K. Sutama. 2000. Pengaruh gliserol dalam pengencer tris terhadap kualitas semen beku kambing peranakan etawah. J. Ilmu Ternak dan Veteriner. $5(2): 1-8$

Tambing, S. N., M. R. Toelihere., T. L. Yusuf., B. Purwantara., I. K. Sutama dan P. Z. Situmorang. 2003. Pengaruh frekuensi ejakulasi terhadap karakterisitik semen segar dan kemampuan libido kambing Saanen. J. Sain Vet. 21(2):57-65.

Wildeus S, 1995. Reproductive Management Of The Meat Goat. Http: //Goat. Clemson. Edu / NC \% 20 Handbook / reproduction. Html. Diakses pada tanggal 1 februari 2018. 